\title{
THE TOPICAL ISSUES OF CODING THE REGIONAL SOCIAL SECURITY LEGISLATION (ON THE EXAMPLE OF THE VOLGOGRAD REGION)
}

\author{
Tatyana V. Derkacheva \\ International Law Institute's Volzhsky Branch, Volzhsky, Russian Federation
}

\begin{abstract}
Introduction: social security is one of the most important elements of the social policy of the state. Many legal acts are adopted in the social security field. In order to ensure the uniform understanding and interpretation of the content of the normative legal acts in the social security field, their systematization as well as the practical application in the law enforcement process the regional legislators have codified the social security legislation in a number of subjects of the Russian Federation. Using the methods of scientific knowledge, especially the method of system analysis, it is found that the complexity of the problem involves the use of both the law-making and law-realization directions and forms of the legal adaptation of the current legislation of the state. The aim of the study is to conduct a comparative analysis of the social codes adopted in the subjects of the Russian Federation, to identify common approaches in the implementation of the law-making activities for the codification of the social security legislation. The system analysis of the law-making process on the codification of the social security legislation in the subjects of the Russian Federation allowed establishing that the adopted codes had significant differences in structure and content. However, having quite significant differences, the codes have a common property - each of them has one common characteristic - a special part of all adopted social codes is built on a categorical principle. Results: on the basis of the analysis some problems of the law-making activity of the regional legislators on the codification of the social legislation are revealed. Conclusions: 1) it is necessary to adopt a number of federal laws: a codified federal law defining the goals and objectives of the social legislation of the Russian Federation and the subjects of the Russian Federation, the federal law on the sources of law, on the delimitation of powers in law-making between the Russian Federation and its subjects; 2) to establish common principles for the country's implementation of social security; 3) to develop a single conceptual framework that provides a single legal regime for regulating relations in the social security sphere; 4) to develop a model regional social code as a model for the regional legislators.
\end{abstract}

Key words: social security, codification, social code of the RF subjects, social support, forms of social assistance, categories of recipients of social safety net.

Citation. Derkacheva T.V. The Topical Issues of Coding the Regional Social Security Legislation (On the Example of the Volgograd Region). Legal Concept, 2019, vol. 18, no. 3, pp. 90-96. (in Russian). DOI: https://doi.org/ 10.15688/lc.jvolsu.2019.3.13

УДК 349.3

Дата поступления статьи: 14.05.2019

ББК 67.405 .2 Дата принятия статьи: 05.06.2019

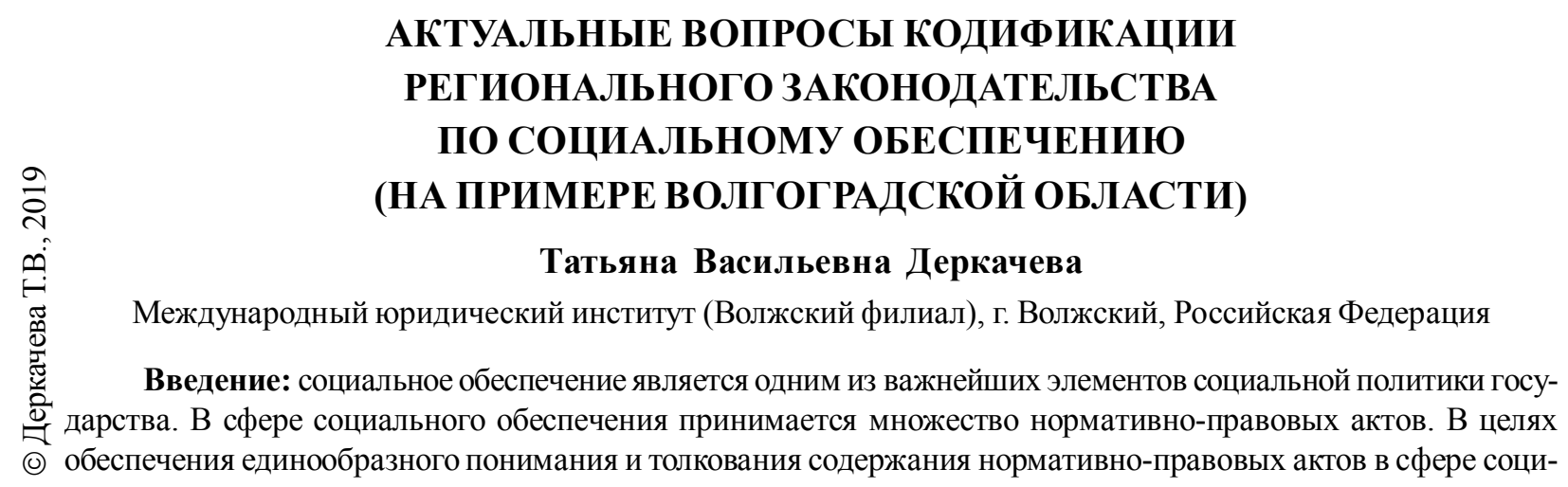


ального обеспечения, их систематизации, а также применения в практической деятельности в процессе правопримения в ряде субъектов Российской Федерации региональными законодателями проведена кодификация законодательства о социальном обеспечении. С помощью методов научного познания, прежде всего метода системного анализа, установлено, что сложность выделенной проблемы предполагает использование как правотворческого, так и правореализационного направления и форм правовой адаптации действующего законодательства исходя из интересов государства. Целью работы является проведение сравнительного анализа Социальных кодексов (далее - Кодекс), принятых в субъектах Российской Федерации, выявление общих подходов при осуществлении правотворческой деятельности по кодификации законодательства о социальном обеспечении. Проведенный системный анализ правотворческого процесса по кодификации законодательства о социальном обеспечении в субъектах РФ позволил установить, что принятые Кодексы имеют значительные отличия по структуре и содержанию. Вместе с тем, имея довольно существенные различия, Кодексы обладают общим свойством: в каждом из них имеется одна общая характерная черта - Особенная часть всех принятых социальных кодексов построена по категорийному принципу. Результаты: на основе проведенного анализа выявлены некоторые проблемы правотворческой деятельности региональных законодателей по кодификации социального законодательства. Выводы: 1) необходимо принять ряд федеральных законов: кодифицированный федеральный закон, определяющий цели и задачи социального законодательства РФ и субъектов РФ, федеральный закон об источниках права, о разграничении полномочий в правотворческой деятельности между Российской Федерацией и ее субъектами; 2) установить общие для страны принципы реализации социального обеспечения; 3) разработать единый понятийный аппарат, обеспечивающий единый правовой режим регулирования отношений в сфере социального обеспечения; 4) разработать модельный региональный социальный кодекс в качестве образца для региональных законодателей.

Ключевые слова: социальное обеспечение, кодификация, социальный кодекс субъектов РФ, социальная поддержка, меры социальной поддержки, категории получателей мер социальной поддержки.

Цитирование. Деркачева Т. В. Актуальные вопросы кодификации регионального законодательства по социальному обеспечению (на примере Волгоградской области) // Legal Concept = Правовая парадигма. 2019. - T. 18, № 3. - C. 90-96. - DOI: https://doi.org/10.15688/lc.jvolsu.2019.3.13

\section{Введение}

Формирование и построение социального государства немыслимо без четко функционирующей системы социального обеспечения, включающей и гарантии государства от социальных рисков, и эффективные формы и методы социальной поддержки населения, круг лиц, имеющих право на социальную поддержку, наличие законодательства, отвечающего современным реалиям в сфере социального обеспечения на федеральном и региональном уровнях.

\section{Кодификация регионального} социального законодательства как оптимальная и эффективная форма его систематизации

Вопросы социального обеспечения находятся в совместном ведении Российской Федерации и ее субъектов согласно Конституции РФ (ст. 72). Социальное обеспечение является важнейшим элементом социальной политики государства, затрагивающим интересы каждого человека. Жизненные реалии та- ковы, что вопросы социального обеспечения требуют от государства на федеральном и региональном уровнях постоянного внимания и совершенствования, установления гарантий от социальных рисков, принятия конкретных мер социальной поддержки отдельным категориям граждан. Современный период развития социального обеспечения характеризуется высоким уровнем правового регулирования общественных отношений. Законодательство в сфере социального обеспечения обладает многогранностью и объемностью. Данные процессы характерны не только для федерального уровня, но и в полной мере относятся к правотворческой деятельности субъектов Российской Федерации.

Региональное законодательство, регулирующее вопросы социального обеспечения, активно развивается, принимается множество законов субъектов Российской Федерации в сфере социального обеспечения. Существующий нормативно-правовой массив нуждается в систематизации и упорядочении, в первую очередь на уровне субъекта РФ. Исходя их конституционно-правового статуса субъекта Российской Федерации, можно сделать вывод, 


\section{ТЕОРИЯ И ПРАКТИКА ГОСУДАРСТВЕННО-ПРАВОВОГО РАЗВИТИЯ}

что субъект Российской Федерации обладает достаточными полномочиями по организации и проведению полномасштабной правотворческой деятельности, в том числе и кодификации. В ряде субъектов Российской Федерации, а именно в Санкт-Петербурге, Ярославской, Белгородской, Омской, Волгоградской и Астраханской областях, региональными законодателями приняты Социальные кодексы. Представляется, что в данных регионах проделана достаточно серьезная и кропотливая работа в условиях довольно объемного массива региональных нормативно-правовых актов по вопросам социального обеспечения и отсутствия федерального закона об источниках права и нормативно-правовом акте, отсутствия федерального закона о разграничении полномочий по нормотворческой деятельности между Российской Федерацией и ее субъектами.

Известно, что на федеральном уровне Социальный кодекс РФ не принят, нет и Кодекса РФ о социальном обеспечении. Указанные федеральные нормативно-правовые акты, несомненно, стали бы для регионального законодателя основанием и моделью в плане юридической техники. В результате отсутствия единого методологического подхода к построению структуры региональных кодексов и его содержанию в процессе регионального правотворчества региональными законодателями принимаются самостоятельные решения.

Исходя из существующих реалий, региональные социальные кодексы имеют различия как по структуре, так и по содержанию. Отличия состоят в количестве содержащихся в кодексах статей. Например, в Кодексе СанктПетербурга [4] насчитывается 120 статей, в Кодексе Ярославской области [5] закреплено 100 статей, Социальный кодекс Белгородской области [1] содержит 79 статей, Омской области - 73 [3], Волгоградской области - 61 статья, Астраханской области - 60 статей.

В ряде региональных Социальных кодексов имеются разделы, куда входят главы. Это Кодексы г. Санкт-Петербурга, Омской и Ярославской областей.

В региональных Социальных кодексах Волгоградской [2], Белгородской и Астраханской областей имеются только главы. Все региональные Социальные кодексы содержат Общую и Особенную части.

Основные термины и понятия содержатся лишь в двух кодексах - в Общей части Кодексов Санкт-Петербурга и Омской области. В остальных Кодексах такие существенные позиции, как определения и термины, в Общей части отсутствуют, что безусловно их обедняет и затрудняет правоприменение.

Особенная часть региональных Социальных кодексов закрепляет порядок оказания социальной поддержки отдельным категориям граждан. В каждой главе содержатся условия оказания социальной поддержки населению по категориям.

Все региональные Социальные кодексы содержат единый механизм по предоставлению социальной поддержки. Региональными Социальными кодексами закреплен механизм предоставления социальной поддержки, исходя из принципа категориальности. Социальные риски, в результате которых и возникают для граждан неблагоприятные последствия, являющиеся основанием для оказания социальной поддержки, региональными Социальными кодексами не учитываются.

Социальный кодекс Волгоградской области был принят Волгоградской областной думой 24 декабря 2015 года [2]. Среди субъектов Российской Федерации, входящих в Южный федеральный округ, это первый подобный опыт и пятый в целом по Российской Федерации, чем и объясняется интерес к принятому кодифицированному акту. Несомненно, принятие Кодекса является актуальной мерой, направленной прежде всего на повышение эффективности действующей системы социального обеспечения в регионе, оптимизацию выделяемых на социальную поддержку из областного бюджета средств и их перераспределение в пользу остронуждающихся граждан, совершенствование отраслевого законодательства по вопросам социального обеспечения.

Анализируя деятельность Волгоградской областной думы как регионального законодателя, которым принят Социальный кодекс, установлено, что при осуществлении правотворческой деятельности по кодификации регионального законодательства в основу были заложены цели кодификации. Преж- 
де всего это приоритетное осуществление субъектом РФ социальной политики на ближайший период и перспективное развитие в отношении пенсионеров, малоимущих и других категорий населения, пострадавших от социальных рисков, повышение уровня нормативно-правового регулирования социальнообеспечительных правоотношений, а также совершенствование технико-юридического качества имеющегося массива социального законодательства.

Повышение уровня правовой информированности граждан как части правовой культуры по вопросам оказания поддержки отдельным категориям населения.

Для достижения целей кодификации регионального законодательства по социальному обеспечению основными задачами являлись:

- установление новых основных принципов предоставления социальной поддержки, адресность и нуждаемость;

- стабилизация действующего регионального законодательства по вопросам социального обеспечения, его хронологизация, системность и обновление, устранение противоречивости и бессистемности;

- повышение уровня правовых знаний, доступность информации, упрощенный порядок поиска нормативно-правового акта в ходе правоприменительной деятельности;

- устранение бессистемности и противоречивости нормативно-правовых актов по вопросам социального обеспечения;

- приоритетность норм, содержащихся в Социальном кодексе, по отношению к вновь принятым законам субъекта по вопросам социального обеспечения.

Проведенная кодификация законодательства о социальном обеспечении Волгоградской области - это не просто механическое объединение действовавших нормативных правовых актов. Это переосмысление всей системы социальной поддержки в регионе, формирование новых принципов ее предоставления, постановка новых актуальных целей и задач, упорядочение действующего и формирование нового понятийного аппарата.

Кодекс Волгоградской области объединил в себе более 200 законов Волгоградской области и подзаконные акты. Он состоит из
8 глав, содержащих 61 статью [2]. Его структура практически сходна со структурой Социальных кодексов Ярославской [5] и Белгородской областей [1].

В главах Особенной части Социального кодекса Волгоградской области содержатся положения, регулирующие оказание социальной поддержки следующим категориям населения (меры социальной поддержки по льготному проезду, государственная социальная помощь, дополнительные меры поддержки): семьям, имеющим детей; ветеранам; военнослужащим и членам их семей; отдельным категоримям граждан, проживающим в сельской местности; детям сиротам и детям, оставшимся без попечения родителей.

\section{Выводы}

Анализируя главы 2-7 Особенной части Социального кодекса Волгоградской области [2], можно сделать вывод, что в нем установлены новые принципы к определению видов и форм социальной поддержки. Прежде всего это показатели нуждаемости и адресности. При определении нуждаемости согласно требованиям, закрепленным в Социальном кодексе, учитываются следующие показатели:

- среднедушевой доход семьи и одиноко проживающего гражданина;

- установленная социальная норма площади жилья в Волгоградской области;

- утвержденные нормативы потребления коммунальных услуг;

- стоимость твердого топлива;

- стоимость бытового газа;

- оценка наличия или отсутствия определенного имущества;

- обязательное трудоустройство трудоспособных граждан или регистрация в качестве безработного в службе занятости;

- учет ограничений, установленных в отношении индивидуальных предпринимателей. При обращении за социальной поддержкой гражданин не должен являться индивидуальным предпринимателем.

При определении величины прожиточного минимума региональный законодатель руководствуется методикой, установленной федеральными законами. 


\section{Заключение}

Таким образом, Социальный кодекс Волгоградской области содержит установленные нормативы социальных гарантий, которые обеспечиваются за счет средств областного бюджета и должны быть предоставлены не ниже установленного уровня.

Представляется, что в целях обеспечения полноты правового регулирования и охвата нормативного материала при подготовке кодифицированного акта следует использовать опыт белгородских законодателей, которые в Общей части Социального кодекса Белгородской области отдельной статьей закрепили показатели нуждаемости (ст. 6 СК БО).

Содержание Социального кодекса и круг регулируемых им общественных отношений позволяет сделать вывод, что его следовало наименовать Кодексом социального обеспечения Волгоградской области.

Главу первую «Общие положения» надлежит дополнить отдельной статьей, посвященной принципам построения системы социального обеспечения по предоставлению мер социальной поддержки и оказания материальной помощи в Волгоградской области [2], как это сформулировано в Социальном кодексе Санкт-Петербурга, а также дополнить содержание Общей части Кодекса понятийным аппаратом, отразить определения основных терминов и понятий, используемых в Кодексе, закрепить показатели нуждаемости, установить критерии малообеспеченности, бедности, единые стандарты социального обеспечения, отразить методику оценки имущественного положения отдельных групп населения, действующую на территории Волгоградской области.

Глава 8 «Заключительные и переходные положения» имеет очень важное значение, поскольку является связующим звеном между прежним и новым правовым регулированием. Статья 58 данной главы содержит перечень утративших силу отдельных законодательных актов Волгоградской области.

В этой связи позволим предположить, что данный перечень утративших силу нормативных актов правильнее разместить в за- коне о вступлении в силу Социального кодекca, а не в тексте самого Кодекса.

Что касается Преамбулы Социального кодекса, то в юридической науке давно сложилась оценка преамбулы как ненормативной части акта. Исходя из этого в Преамбуле Социального кодекса целесообразнее заложить основные идеи принятия этого документа обеспечение достойного уровня жизни жителям Волгоградской области, исполнение принятых субъектом Российской Федерации социальных обязательств, о моральной ответственности перед старшим поколением, защитниками Сталинграда, детьми Сталинграда. Данные декларативные нормы Преамбулы могут стать своеобразным ориентиром правотворческой деятельности на перспективу и повысить воспитательное значение Социального кодекса.

Из проведенного анализа Социального кодекса Волгоградской области, а также обращения к нормам Социальных кодексов других субъектов Российской Федерации возникает предложение о принятии на уровне Федерации модельного акта в качестве образца для законодателей субъектов Российской Федерации, учитывая важность и значимость общественных отношений, регулируемых Социальными кодексами субъектов Российской Федерации. Развитие общественных процессов, экономическая ситуация свидетельствуют о том, что остро назрела необходимость в принятии кодифицированного федерального закона, обеспечивающего правовое регулирование правоотношений социального обеспечения граждан. Именно на федеральном уровне должны быть определены основные цели и задачи социально-обеспечительного законодательства РФ и субъектов РФ. Нормы федерального закона позволят детализировать конституционные принципы реализации социального обеспечения, установить новые понятия и основные термины, которые будут способствовать единообразию в правоприменении и обеспечат единый правовой режим регулирования социально-обеспечительных отношений. Очевидно, что с принятием такого федерального закона значительно активизируется правотворческая деятельность в субъектах РФ. В настоящее время большинство региональных законодателей занимают выжидательную 
позицию и не торопятся с принятием региональных Социальных кодексов. Несомненно деятельность субъектов-первопроходцев по принятию региональных Социальных кодексов является одним из важных этапов в формировании многоуровневой правовой основы социального обеспечения и будет способствовать принятию и Социального кодекса на федеральном уровне

Сделанные выводы и предложения являются лишь попыткой проанализировать содержание такого важного и необходимого нормативного акта, как Социальный кодекс субъектов Российской Федерации, и высказать определенные суждения по его структуре и содержанию.

\section{СПИСОК ЛИТЕРАТУРЫ}

1. Закон Белгородской области от 28.12.2004 № 165 «Социальный кодекс Белгородской области» : (принят Белгородской областной Думой 09.12.2004) // Белгородские известия. -2004. - 29 дек. - № 226-227.

2. Закон Волгоградской области от 31.12.2015 № 246-ОД «Социальный Кодекс Волгоградской области» : (принят Волгоградской областной Думой 24.12.2015) // Волгоградская правда. - 2016. - № 6 (19 янв.).

3. Закон Омской области от 04 июля 2008 г. № 1061-О3 «Кодекс Омской области о социальной защите отдельных категорий граждан» // Электронный фонд правовой поддержки нормативно-технической документации. - Режим доступа: http:// docs.cntd.ru/document/943027040.

4. Закон Санкт-Петербурга от 22 ноября 2011 г. № 728-132 «Социальный кодекс Санкт-Петербурга» : (принят Законодательным Собранием СанктПетербурга 9 ноября 2011 года). - Доступ из справ.правовой системы «Гарант». - Режим доступа: http://base.garant.ru/35358030/\#ixzz3zqhGzWqz.

5. Закон Ярославской области от 19 декабря 2008 г. № 65-3 «Социальный кодекс Ярославской области» // Электронный фонд правовой поддержки нормативно-технической документации. - Режим доступа: http://docs.cntd.ru/document/934023342.

\section{REFERENCES}

1. Zakon Belgorodskoy oblasti ot 28.12.2004 № 165 «Sotsialnyy kodeks Belgorodskoy oblasti»: (prinyat Belgorodskoy oblastnoy Dumoy 09.12.2004) [Law of the Belgorod Region of December 28, 2004 No. 165 "Social Code of the Belgorod Region" (adopted by the Belgorod Regional Duma December 9, 2004)]. Belgorodskie izvestiya [Belgorod News], 2004, Dec. 29, no. 226-227.

2. Zakon Volgogradskoy oblasti ot 31.12.2015 № 246-OD «Sotsialnyy Kodeks Volgogradskoy oblasti»: (priniat Volgogradskoy oblastnoy Dumoy 24.12.2015) [The Law of the Volgograd Region dated 12/31/2015 No. 246-OD "Social Code of the Volgograd region" (adopted by the Volgograd Regional Duma 12/24/2015)]. Volgogradskaya Pravda, 2016, no. 6(19 Jan.).

3. Zakon Omskoy oblasti ot 04 iyulya $2008 \mathrm{~g}$. № 1061-OZ «Kodeks Omskoy oblasti o sotsialnoy zashchite otdelnykh kategoriy grazhdan» [The Law of the Omsk Region of July 4, 2008 No. 1061-OZ "Code of the Omsk region on the social protection of certain categories of citizens"]. Electronic fund for legal support of normative-technical documentation. URL: http://docs.cntd.ru/document/943027040.

4. Zakon Sankt-Peterburga ot 22 noyabrya 2011g. № 728-132 «Sotsialnyy kodeks SanktPeterburga»: (prinyat Zakonodatelnym Sobraniem Sankt-Peterburga 9 noyabrya 2011 goda) [Law of St. Petersburg dated November 22, 2011 No. 728-132 "Social Code of St. Petersburg" (Adopted by the Legislative Assembly of St. Petersburg November 9, 2011)]. URL: http://base.garant.ru/35358030/\#ixzz3 zqhGzWqz.

5. Zakon Yaroslavskoy oblasti ot 19 dekabrya 2008 g. № 65-z «Sotsialnyy kodeks Yaroslavskoy oblasti» [Law of the Yaroslavl Region of December 19, 2008 No. 65-z "Social Code of the Yaroslavl Region"]. Electronic fund for legal support of normativetechnical documentation. URL: http://docs.cntd.ru/ document/934023342. 


\section{ТЕОРИЯ И ПРАКТИКА ГОСУДАРСТВЕННО-ПРАВОВОГО РАЗВИТИЯ}

\section{Information about the Author}

Tatyana V. Derkacheva, Candidate of Sciences (Jurisprudence), Associate Professor, Department of Theory of Law and State Legal Disciplines, International Law Institute's Volzhsky Branch, Bolshevistskaya St., 7, 404106 Volzhsky, Russian Federation, derkacheva_tv@mail.ru, https://orcid.org/ 0000-0002-7125-9154

\section{Информация об авторе}

Татьяна Васильевна Деркачева, кандидат юридических наук, доцент кафедры теории права и государственно-правовых дисциплин, Международный юридический институт (Волжский филиал), ул. Большевистская, 7, 404106 г. Волжский, Российская Федерация, derkacheva_tv@mail.ru, https://orcid.org/0000-0002-7125-9154 